\title{
Retailers' Merchandise Organization and Price Perceptions
}

Final version: $\underline{\text { http://dx.doi.org/10.1016/j.jretai.2011.02.005 }}$

Rajneesh Suri is Associate Professor of Marketing, LeBow College of Business, Drexel University, $32^{\text {nd }}$ and Market Streets, Philadelphia PA 19104; TEL: 215.895.6980, FAX: 215.895.6975, e-mail: surir@drexel.edu.

Jane Zen Cai is Assistant Professor of Marketing, College of Business Administration, University of Rhode Island, Kingston, RI, 02881; TEL: 401.874.4372, FAX:

401.874.4312, e-mail: janecai@uri.edu

Kent B. Monroe is J. M. Jones Distinguished Professor of Marketing Emeritus, University of Illinois, Urbana-Champaign and Distinguished Visiting Scholar, University of Richmond, Richmond, VA, 4905 Old Millrace Place, Glen Allen, VA 23059; TEL: 804-716-2395, e-mail: kentmonroe@verizon.net.

Mrugank V Thakor is Associate Professor of Marketing, Concordia University, John Molson School of Business, Concordia University, 1455 de Maisonneuve Blvd. West, Montreal Quebec H3G 1M8, Canada. Phone: (514) 848-2424 ext 2999; email mthakor@jmsb.concordia.ca 


\title{
Retailers' Merchandise Organization and Price Perceptions
}

\begin{abstract}
Retailers' presentation of merchandise to consumers is often organized by brand or by price to facilitate comparison and processing of competitive information. While such organization of product information is presumed to assist consumer decisionmaking, we suggest that sorting of alternatives on brand names strain cognitive resources more than a price sort, leading to differences in sensitivity to prices for a target product accompanying these two sorts. We conduct three studies to examine this issue and find that sorting of alternatives interacts with consumers' motivation and influences price perceptions. Our results add nuance to the findings from previous studies examining how assortment affects consumers' price sensitivity, and suggest that retailers whose appeal is not primarily price-based could benefit by presenting merchandise information sorted by brand name so as to increase perceptions of quality and value.
\end{abstract}

Keywords: Price, Information Sort, Motivation, Information Processing, 
Consumers have multiple options today across a broad variety of product categories, with the attendant challenge of evaluating a product while screening and interpreting a large amount of information on alternatives. It has been recognized that as retailers try to attract consumers by offering large product assortments, they also increase consumers' processing costs, paradoxically reducing their assortments' attractiveness (Boyd and Bahn 2009). Thus, to assist consumers in their choice task retailers organize and merchandise product categories by brand (e.g., Sony high-definition TV's being grouped together) or by price. On the Internet, consumers are empowered by electronic decision aids that assist them in filtering and sorting information (Haubl and Murray 2006), leading some to suggest that the most important benefit of online shopping to consumers is not greater product selection but electronic screening (Alba et al. 1997).

Prior research has established that sorting information on alternatives significantly reduces consumers' decision-making effort, improves decision quality (Diehl, Kornish and Lynch 2003), and increases the importance of attributes included in the selection criteria (Haubl and Murray 2003). Consistent with this conclusion, Haubl and Trifts (2000) showed that sorting on price made consumers more sensitive to the price paid. However, Lynch and Ariely (2000) found that consumers paid higher average prices in the presence of a price sort than when it was absent, leading them to conclude that price sort did not reliably affect price sensitivity.

These conflicting conclusions raise an issue as to how sorting alternatives on price influences consumers' evaluations of products and prices. Furthermore, since consumers prefer to view competitive information arranged on attributes or alternatives (Ariely 2000), another related issue is whether alternatives sorted on price influence consumers' sensitivity to price differently than a brand sort. Though retailers present their merchandise in stores and online in 
several different ways, these two sorts are popular among retailers as they are simple to execute. Hence, these two types of sorts form the focus of this research.

Our conceptualization proposes to resolve contradictory results on the effects of price sort, and suggests that motivation to process information moderates the effect of sorting information on consumers' sensitivity to price. Specifically, motivation to process information makes consumers focus more on product attributes including price of a focal product when the accompanying alternatives are sorted on price rather than on brand names. We also demonstrate that cognitive difficulty experienced while processing information in these two sorts causes these differences in evaluation. We report three studies to test these predictions.

\section{CONCEPTUAL DEVELOPMENT}

Consumers often perform a primary task requiring an understanding of information on a product of interest (focal product), and a secondary task of managing information on competitive products. Behavioral researchers have been intrigued by peoples' inability to perform such multiple activities concurrently. "People have severe limitations on their ability to carry out simultaneously certain cognitive processes that seem fairly trivial" (Pashler 1994, p. 241). While not denying the interference created by concurrent tasks, it has been argued that if competitive information is managed effectively it could have a positive effect on the evaluation of a focal product (Ariely 2000; Hoffman and Novak 1996). This positive effect comes from the intrinsic nature of the information itself, while the negative effect stems from the additional cognitive resources required by such a task. The cognitive resources allocated to managing information on the alternatives will be integrally linked with the act of making sense of the main task of evaluating a focal product (Ariely 2000). A reduction in cognitive effort required to manage such information will free up cognitive resources required to integrate this information and make 
judgments about a focal product. Hence, ability to process information on a focal product will depend upon not only the cognitive effort devoted to the task but also the cognitive resources consumed when managing information on the accompanying alternatives (Kleinmuntz and Schkade 1993). The issue we investigate is of how the sorting of alternatives influences consumers' ability to manage such information.

\section{Effects of Sorting}

Sorting of alternatives can lower search costs for quality information by saving consumers the trouble of directly inspecting quality information on products (Alba et al. 1997; Diehl et al. 2003). If a sort does not produce such reductions in search costs, consumers are likely to express ambiguity about their product decisions and spend greater cognitive resources making sense of a sorted list (Ariely 2000). Baddeley (2000) argued that the ability to evaluate non-diagnostic information requires substantial attentional components of working memory and manipulating such a sequence may involve multiple mental operations (Lopes, 1982; Teasdale et al., 1999). Choice sets created by structuring alternatives based on price or brand names are however not equivalent in decreasing consumers' cognitive burden when they make choices. Unlike product features like price that are precise, "brand name advantages are often ambiguous and associated with high uncertainty" (Simonson, Nowlis and Lemon 1993, p.365). For instance, a price of an alternative being $\$ 10$ higher than a competing choice leaves little doubt about the additional monetary sacrifice required to purchase that product. But knowing a laptop from Dell is superior to one from HP or Toshiba is rather tentative and makes trade-offs between brands difficult to assess. Hence, a brand sort may strain consumers' cognitive resources and hamper their ability to process information about a target product. On the other hand, processing alternatives in a price sort will be cognitively less taxing and free up cognitive resources to 
process information about a target product. Consistent with this argument Haubl and Trifts (2000) found that when alternatives were sorted on an attribute, the perceived difficulty of comparison amongst products was significantly lower than when such information was not sorted on a specific attribute. This ease of comparison (or lack thereof) underlies the difference in the effects of brand and price sorts on the assessment of target product information.

\section{Sorting and Motivation to Process Information}

Regardless of the effects of a sort on consumers' information processing, if they are not motivated to use the information, there is little reason for them to expend the necessary cognitive resources. Chaiken and Trope (1999) suggest that when there is motivation and ability to process information, consumers will scrutinize task relevant information. However, if there is low motivation to process information, or if the cognitive resources are constrained, consumers will rely on heuristics as such processing takes less effort. Given differences in the impact of brand name and price sorts on cognitive effort required to assess information on alternatives, when the alternatives are sorted on price, sufficient cognitive resources will be available to process information on a focal product. On the other hand, sorting on brand names will co-opt cognitive resources that would have otherwise been available to process the target information. Hence, in high motivation conditions, when alternatives are sorted on price, sufficient cognitive resources will be available to scrutinize target information. However, a brand sort will lead to a less effortful (heuristic) processing of target information. Also when motivation to process information is low, irrespective of how alternatives are sorted, a similar heuristic processing of target information will be expected. 


\section{Processing of Price Information}

To develop hypotheses on how sorting of alternatives will influence consumers' judgments we consider when consumers use price information more to infer a product's quality or to assess its monetary sacrifice (Monroe 2003). In contexts that prevent consumers from systematically processing the available information, relatively less weight will be placed on the price-sacrifice relationship and price will be used more to infer a product's quality (Suri and Monroe 2003). However, when consumers process information systematically, attributes in addition to price will be used to judge a product's quality. In such a situation price will be used less as an indicator of quality and more weight will be placed on the price-sacrifice relationship when evaluating a product (Rao and Monroe 1988).

\section{HYPOTHESES}

Consumers have an acceptable price range for products (Rao and Sieben 1992). Since prices at the ends of this range disproportionately influence consumers' judgments about a product (Monroe 2003), we developed predictions about the effects of sorting on the evaluation of prices at the high and low end of a price range.

\section{High Motivation Condition}

When motivation to process information is high and alternatives are sorted on price, cognitive resources will be available to systematically process product information and a target's price will serve more as an indicator of monetary sacrifice. Consequently a relatively low (high) price target will be perceived as low (high) in monetary sacrifice. On the other hand, when alternatives are sorted on brand names, availability of cognitive resources will be limited and consumers will process price information heuristically, leading them to use a low (high) price of a target to infer that the product is of low (high) quality. Since consumers consider both the 
price-quality and the price-sacrifice relationships when evaluating products, the more weight they place on price as an indicator of quality, the less weight they will place on price as an indicator of sacrifice (Suri and Monroe 2003). Therefore,

Hypothesis 1): When motivation to process information is high for a relatively low (high) price target, and alternatives are sorted on brand names, then:

a) perceptions of quality will be lower (higher) than when the alternatives are sorted on price.

b) perceptions of sacrifice will be higher (lower) than when the alternatives are sorted on price.

Given that perceived value of an offer represents a mental trade-off between perceptions of quality and sacrifice, it is expected that these judgments of value will increase with an increase in perceived quality or a decrease in perceived sacrifice (Monroe 2003). Thus:

Hypothesis 1c): When motivation to process information is high for a relatively low (high) price target product, and alternatives are sorted on brand names, then the perceptions of value will be lower (higher) than when the alternatives are sorted on price.

\section{Low Motivation Condition}

When motivation to process information is low, insufficient cognitive resources are allocated to the task, and regardless of the sort, consumers will heuristically process the target information. Consequently, it is expected that:

Hypothesis 2): For both low and high-price targets, the perceptions of sacrifice, quality, and value will not be different between the two sorts. 
These hypotheses were tested using three experiments with different products and evaluation contexts. Studies 1 and 2 used a paper-pencil task and two different scenarios to manipulate motivation to process information. To examine differences in cognitive constraints created by the two sorts, study 2 also manipulated memory load following a dual task paradigm. Using an online context, study 3 replicated the effects of sorting and collected additional measures examining cognitive difficulty and depth of information processing in the two sorts.

\section{STUDY 1}

We have argued that when consumers are motivated to process information, a price sort increases focus on a target product enhancing attention to its price. We manipulated motivation to process information by providing written scenarios with varied personal relevance.

\section{Stimuli Creation and Procedure}

Pretests led to the selection of Philips DVD players $(\$ 189.99, \$ 89.99)$ as stimulus with twenty additional players forming a list of accompanying alternatives (see Appendix 1 for products and prices). The data were collected using a 2 (motivation: low, high) x 2 (price level: low, high) x 2 (information sort: price, brand names) between subjects design with 113 undergraduate students (55\% females, average age 22.5 years) who participated for extra credits. The DVD players were either sorted on ascending price or on brand names (from A -Z).

The study was conducted in small group sessions with participants randomly assigned to experimental conditions. The sorting of information in online environments was adapted to a paper and pencil task. Using a scenario approach adapted from Howard and Kerin (2006) participants in high motivation conditions were asked to imagine a need to purchase a DVD player. On the other hand, in low motivation conditions the vignette suggested to participants that they had recently purchased a DVD player before being presented the target information. 
After reviewing the target information, participants were provided with an information booklet containing sorted descriptions of additional digital players. In addition, prior to responding to dependent measures (Appendix 1) and knowledge of DVD players (9 point scale: know a lot / little), participants took two and a half minutes to write all thoughts and ideas that they experienced while evaluating the target player and an additional minute to recall target product information (e.g., Maheswaran and Sternthal 1990).

\section{Results}

The motivation to process information (see Appendix 1 for measures) differed between the motivation conditions $\left(M_{\text {high motivation }}=4.84\right.$ vs. $\left.M_{\text {low motivation }}=4.14 ; t_{(111)}=2.24, p<.05\right)$ and the high price was perceived more expensive $\left(M_{\text {low price }}=3.60\right.$ vs. $M_{\text {high price }}=5.70 ; t_{(111)}=8.32$, $p<.001)$. There was a significant motivation $\mathrm{x}$ price level $\mathrm{x}$ information sort effect on perceptions of quality $\left(F_{(1,106)}=6.00, p<.05\right)$, sacrifice $\left(F_{(1,105)}=11.82, p<.01\right)$ and value $(F$ $(1,105)=12.92, p<.001)$, with prior knowledge showing no significant effects as a covariate $\left(F_{(3,}\right.$ $103)=1.92, p>.10)$. Source of the three way interactions were the diverging pattern of results in the motivation conditions. In high motivation conditions, the sorting of alternatives on price lowered perceptions of quality $\left(F_{(1,26)}=5.00, p<.05\right)$ and value $\left(F_{(1,26)}=13.47, p<.01\right)$ but raised the perceptions of sacrifice $\left(F_{(1,26)}=5.32, p<.05\right)$ for the high price player (see Table 1 for cell means). For the low price player participants perceived the target to be lower on perceptions of sacrifice $\left(F_{(1,24)}=4.71, p<.05\right)$, higher on perceptions of value $\left(F_{(1,24)}=10.20, p\right.$ $<.01)$ and quality $\left(F_{(1,24)}=3.24, p<.07\right)$ when the alternatives were sorted on price than on brand names. As anticipated, in low motivation conditions, there were no significant differences between the two sorts on these dependent measures $(p>.10$; Table 1).

-----Insert Table 1 about here---- 


\section{Cognitive Responses and Attribute Recall}

It was expected that in high motivation conditions target product information would be elaborated more thoroughly and recalled more accurately if the alternatives were sorted on price than on brand names. On the other hand, when motivation to process information is low, cognitive effort spent on processing product information would be low and similar between the two sorts. To determine such processing differences the thought processes were analyzed.

After examining a few written protocols, a coding scheme was developed. Four categories of thoughts were evident from the data: 1) elaborated thoughts that referred to product attributes, including its monetary sacrifice or product benefits (e.g., "the price was a bargain relative to the features"; "how many DVDs can it play"); 2) heuristic thoughts that relied on price or brand name to infer quality ("cheaper DVD players are useless"; "Philips is a pretty good brand"); 3) imagery thoughts related to product imagery ("I can think of the features I would like in my player"), knowledge or familiarity with digital players ("I am not very knowledgeable about DVD players"), and the task ("color pictures would have been nice"); 4) unrelated thoughts that included all responses not related to the task ("it is such a nice day outside"). Participants' responses were coded by two independent judges (reliability: $I_{r}=.88$ ) and two proportions of thoughts—-based on elaborated thoughts and non-elaborated thoughts (included heuristic and imagery thoughts) — to total thoughts $(M=3.6, S D=1.75)$ were computed (e.g., Maheswaran and Sternthal 1990).

There were main effects of motivation (elaborated: $F_{(1,99)}=46.64, p<.001$; nonelaborated: $\left.F_{(1,99)}=35.04, p<.001\right)$ and information sort (elaborated: $F_{(1,99)}=68.6, p<.001$; non-elaborated: $\left.F_{(1,99)}=45.59, p<.001\right)$ and also a motivation and information sort interaction (elaborated: $F_{(1,99)}=62.46, p<.001$; non-elaborated: $\left.F_{(1,103)}=45.28, p<.001\right)$. In high 
motivation conditions, the brand sort led to fewer elaborated thoughts and more non-elaborated thoughts while in low motivation conditions the differences between the two sorts on these thoughts was not significant. The judges also coded recall information of the target's attributes and disagreements (8\%) were resolved by discussion. Recall accuracy for each participant was determined using a ratio of the correct attributes $(M=2.47)$ to the total attributes recalled $(M=$ 3.72). Similar to thought measures, there were main effects of motivation $\left(F_{(1,89)}=12.23, p<\right.$ $.001)$ and information sort $\left(F_{(1,89)}=15.17, p<.001\right)$ and a motivation $\mathrm{x}$ information sort effect on recall accuracy $\left(F_{(1,93)}=9.13, p<.01\right)$. Only in high motivation conditions, participants were significantly more accurate when alternatives were sorted on price than on brand names with no significant differences in accuracy between the two sorts in low motivation conditions (Table 3).

\section{Discussion}

In high motivation conditions and when the accompanying alternatives were sorted on price rather than on brand names, the target information was elaborated thoroughly and its price was used more to evaluate monetary sacrifice than to infer its quality. In low motivation conditions, differences between the two sorts on evaluations of the target were not significant and price was used less to judge its monetary sacrifice. These initial results support our thesis that compared to a sorting on price, a brand sort leads to less thorough elaboration of target information. However the underlying reason that such results were due to differences in cognitive difficulty that these sorts created could only be conjectured.

Hence, in study 2 we used a dual-task interference paradigm and embedded the primary task of evaluating a target as participants performed a secondary task. If sorting alternatives on price allows consumers to process target information carefully then when such cognitive resources are usurped by a secondary (memory load) task it should reduce the difference between 
the two sorts on the evaluations of the target. In addition different motivation scenarios were used to manipulate personal relevance to participants and test the robustness of our results.

\section{STUDY 2}

\section{Stimuli Creation and Procedure}

Pretests were used to select a GPS device (acceptable price range: \$129- \$700) as stimulus. Additional pretests were used to finalize descriptions for 13 competing GPS devices. For this study only a low price target (Garmin Nuvi GPS: \$149.99) was used and its evaluation was embedded within the dual task procedure. The secondary task consisted of short-term retention and rehearsal of a memory load consisting of either two (low load) or six (high load) letters while evaluating the target product. Participants were told to read each letter, say it aloud and to retain the letters in memory while evaluating product descriptions that followed.

The data were collected using a 2 (information sort: brand, price) x 2 (motivation: low, high) x 2 (memory load: low, high) between subjects design with 161 undergraduate students (52\% males; average age 20.9 years) participating for course credits. Two vignettes were used to create the low (high) motivation condition where participants were told that, "This survey is conducted by a nationally renowned retailer. It is conducting a survey with a small group of participants in distant markets (local city) about a product that it will soon begin marketing. Since you are part of a large (select) group of respondents your opinions are (highly) relevant and will be kept anonymous and averaged across all participants (would be weighed heavily in the decisions about the product)." In high motivation conditions, completed surveys were also entered into a lottery with two $\$ 50$ cash prizes. Similar to study 1 after presenting a role play scenario the target product was presented, followed by a sorted (price or brand name) list of 
products and participants responded to the dependent measures (Appendix 1). In addition cognitive responses were collected and participants recalled the assigned letters.

\section{Results}

The motivation conditions differed on the motivation to process information $\left(M_{\text {high }}\right.$ motivation $=4.61$ vs. $\left.M_{\text {low motivation }}=3.79 ; t_{(159)}=2.90, p<.01\right)$ and participants correctly identified the sorting condition used in the accompanying booklets. First performance on the secondary task was analyzed. Next, using responses from those with accurate recall in this secondary task, the predicted effects of motivation and information sort were tested.

Accurate recall of letters in the secondary task was defined as recalling all letters in the assigned letter sets. Analyzed as a function of three independent variables, recall accuracy revealed only main effects of memory load $\left(F_{(1,153)}=5.51, p<.05\right)$ and information sort $\left(F_{(1,153)}\right.$

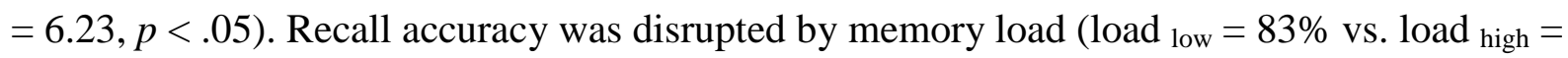
$\left.69 \%, \chi^{2}(1)=4.82 p<.05\right)$ but did not differ between motivation conditions $(p>.10)$. More informative was the lower recall accuracy in brand sort conditions (Sort price $=85 \%$ vs. Sort brand $\left.=68 \%: \chi^{2}(1)=6.01, p<.01\right)$ suggesting a debilitating effect of brand sort on the secondary task.

Using responses from only those participants who recalled the assigned letters accurately $(n=122)$, there was a motivation $\mathrm{x}$ memory load $\mathrm{x}$ information sort effect on perceptions of quality $\left(F_{(1,114)}=4.56, p<.05\right)$, sacrifice $\left(F_{(1,114)}=5.88, p<.05\right)$ and value $\left(F_{(1,114)}=5.53, p<\right.$ $.05)$ with prior knowledge showing no significant effects as a covariate $(\mathrm{p}>.10)$. There were also main effects of the three independent variables but only on perceptions of sacrifice. The target (relatively low price) was perceived lower in monetary sacrifice when: information was sorted on price $\left(F_{(1,120)}=3.92, p<.05\right)$, motivation was high $\left(F_{(1,120)}=4.65, p<.05\right)$ and memory load was low $\left(F_{(1,120)}=6.25, p<.05\right)$. 
It was only in high motivation-low information load conditions that the price sort resulted in the target being perceived lower in monetary sacrifice and higher in quality and value compared to the brand sort (Table 2). In the high memory load and in low motivation conditions the differences between the two sorts were not significant $(p>.10)$. This diverging pattern of results when memory load was low but not when it was high confirmed that increasing memory load disrupted available cognitive resources in price sort but not in brand sort conditions. ----Insert Tables 2 and 3 here---

\section{Cognitive Responses and Attribute Recall}

The cognitive responses (reliability: $I_{r}=0.85 ; M_{\text {total thoughts }}=3.5$ ) and target's attribute recall ( $2 \%$ disagreements; $M_{\text {accurate }}=1.09$ vs. $\left.M_{\text {total }}=2.69\right)$ were coded by two independent judges and revealed effects of information load and sorting. When alternatives were sorted on price than on brand names there were more elaboration thoughts $\left(\right.$ Sort $_{\text {price }}=.15 \mathrm{vs}$. Sort ${ }_{\text {brand }}=$ $\left..04 ; F_{(1,118)}=11.56, p<.01\right)$ and higher attribute recall accuracy (Sort price $=.47$ vs. Sort brand $=$ $\left..30 ; F_{(1,113)}=8.72, p<.01\right)$. The pattern of results was reverse for non-elaboration thoughts $(F$ $(1,118)=11.56, p<.01)$. The effects of sorting were qualified by memory load $\mathrm{x}$ motivation $\mathrm{x}$ information sort effects on thoughts (non-elaborated: $F_{(1,115)}=27.05, p<.001$; elaborated: $F_{(1}$, $115)=52.8, p<.001)$ and recall accuracy $\left(F_{(1,111)}=3.33, p=.07\right)$.

The motivation $\mathrm{x}$ information sort interactions were significant in low memory load (nonelaborated: $F_{(1,58)}=39.97, p<.01$; elaborated: $F_{(1,58)}=189.31, p<.01$; recall accuracy: $F_{(1,54)}$ $=11.96, p<.001$ ) but not in high memory load conditions (non-elaborated: $F_{(1,54)}=1.90, p>$ .10 ; elaborated: $F_{(1,56)}=.10, p>.10$; recall accuracy: $\left.F_{(1,53)}=.45, p>.10\right)$. Thus, increasing load on memory disrupted performance more for the price sort rather than brand sort conditions. 
In high motivation conditions when alternatives were sorted on price, the disrupting effect of memory load occurred for elaboration thoughts $\left(F_{(1,27)}=136.05, p<.001\right)$ and recall accuracy $\left(F_{(1,27)}=24.13, p<.001\right.$; Table 3 for cell means $)$. However, there was no significant effect of memory load when alternatives were sorted on brand names (elaboration: $F_{(1,32)}=2.40$, $p>.10$; recall: $\left.F_{(1,32)}=.04, p>.10\right)$. The non-elaboration thoughts showed a reverse pattern of results for the price sort condition confirming that participants found a brand sort cognitively onerous. When memory load increased the differences between the two sorts diminished. In low motivation conditions, no significant effects of memory load for both information sorts occurred.

\section{Discussion}

As in study 1, the results in low memory load conditions revealed that when participants were motivated, compared to a brand sort, a sorting on price allowed thoughtful elaboration of target information. Increasing memory load however co-opted the available cognitive resources and impaired participants' ability to elaborate on target information even when the alternatives were sorted on price. On the other hand, confirming that a brand sort is cognitively demanding, an increased cognitive demand from the secondary task did not change the processing of target information or its evaluations. These results confirm that compared to a brand sort, a price sort is less demanding of cognitive resources and allows participants to use a target's price more to judge monetary sacrifice than use it to infer a product's quality.

By using different scenarios to manipulate motivation conditions, this study provides further support for the moderating role of motivation on the processing of target information accompanying the two sort conditions. One vexing issue however persists. Since humans are inherently flexible and can reorient themselves when confronted with multiple tasks (HermerVazquez, Spelke, Katsnelson 1999), the issue remains whether a price sort frees up cognitive 
resources to process competing product information, or merely allows consumers to spend additional cognitive resources on processing the focal product. Studies 1 and 2 assessed the effects of sorting of alternatives on the elaboration of target information but whether participants processed the accompanying alternatives differently in the two sorts was not measured. By examining time spent processing the target information and also the accompanying alternatives, study 3 replicates the effects of sorting on processing of target information in the previous studies and also addresses the question of whether sorting leads to differences in processing of the alternatives. An online website was used and the web server unobtrusively captured mouse clicks to track participants' information processing. This approach provided an opportunity to assess depth of processing for the target product as well as the alternatives. Measures assessing perceived difficulty when processing the sorted alternatives provided additional insights.

\section{STUDY 3}

\section{Stimuli and Procedure}

Descriptions for twelve laptop computers were created from online promotions and pretests led to the selection of a low (\$799.99) and high (\$1299.99) price for a HP laptop. A 2 (price: low vs. high) x 2 (motivation: low vs. high) x 2 (information sort: price $\mathrm{x}$ brand) between subjects design used 15 undergraduate students (40\% males; average age 20.95 years) in each condition. The motivation conditions were adapted from study 2 and product information was presented using a webpage split into multiple panes. The left pane listed 13 products including the target product (HP laptop T5800) which appeared at the top of this list. Each product was listed with a brief product description and a hypertext link that led to detailed product descriptions including price in the right pane. Only one detailed product description was displayed at a time and participants could revisit the products as needed. The server tracked 
participants' mouse-clicks to capture the number of alternatives and time spent on each product thus providing measures to assess depth of information search. After reviewing product information participants completed an online survey. The manipulation checks, dependent variables and cognitive responses were adapted from previous studies and participants indicated their knowledge of laptops and experience with online shopping (9 point scale: a little / a lot).

Similar to studies 1 and 2, the alternatives were pre-arranged to simulate either brand name or price sort with the objective of magnifying the power of the manipulation (e.g., Diehl and Zauberman 2005). Using 9 point scales participants indicated difficulty when processing information on the sorted alternatives (not at all / very) and preference to re-arrange alternatives to a competing sort (strongly prefer to sort on: brand/ price).

\section{Results}

There were differences in the perceived price of the two target laptops $\left(M_{\text {high price }}=5.62\right.$ vs. $\left.M_{\text {low price }}=4.58 ; t_{(118)}=8.50, p<.01\right)$ and on motivation to process information $\left(M_{\text {high }}\right.$ motivation $=4.73$ vs. $\left.M_{\text {low motivation }}=3.84 ; t_{(118)}=3.28, p<.05\right)$. All participants also accurately recalled the information sort used on the website. There was a three-way interaction of motivation, information sort and price levels on perceptions of quality $\left(F_{(1,112)}=7.81, p<.01\right)$, sacrifice $\left(F_{(1,112)}=4.34, p<.05\right)$ and value $\left(F_{(1,112)}=5.06, p<.05\right)$ with neither prior knowledge of laptops nor past experience with online shopping showing effects as covariates $(\mathrm{p}>.10)$.

As in studies 1 and 2, in high motivation conditions, a low price target was perceived lower in sacrifice but higher in quality and value in price sort than in brand sort conditions (Table 1). The high price target showed a reverse pattern of results. In low motivation conditions differences between the two sorts on these dependent variables were not significant $(p>.10)$. 
It is expected that since processing of alternatives in a brand sort strains cognitive resources, participants will spend fewer cognitive resources when evaluating the accompanying target information. To examine this possibility, additional measures assessing difficulty processing information on the target and the depth of information search were analyzed.

Difficulty in Processing. Participants perceived evaluating the target more difficult when alternatives were sorted on brand names $\left(M_{\text {brand sort }}=5.7\right.$ vs. $M_{\text {price sort }}=5.0 ; F_{(1,112)}=4.29, p<$ $.05)$ and preferred to rearrange alternatives to a price sort $\left(M_{\text {brand sort }}=6.9\right.$ vs. $M_{\text {price sort }}=6.08 ; F$ $(1,112)=2.68, p<.09)$. A motivation $\mathrm{x}$ information sort interaction (perceived difficulty: $F_{(1,112)}=$ $4.24, p<.05$; rearrange to a price sort: $\left.F_{(1,112)}=11.14, p<.01\right)$ qualified these effects. As Table 4 reveals, irrespective of the price of the target, in high motivation conditions there were significant differences between the two sorts on these measures; alternatives sorted on price were considered less onerous to process than when sorted on brand names.

Baron and Kenny's (1986) criteria for mediation were used to assess whether inclusion of perceived difficulty as a covariate weakened the effects of motivation and information sort. As shown above these independent variables significantly affected both the dependent variables and also perceived difficulty. However, perceptions of difficulty did not differ across the two price levels $(p>.70)$. This result is not surprising and there are no a priori reasons to expect difference across prices. Therefore, we tested the effects of perceived difficulty as a covariate separately for the two price conditions. A regression revealed significant effects of perceived difficulty on perceptions of sacrifice $\left(\beta_{\text {low price }}=.30, p<.05 ; \beta_{\text {high price }}=-.28, p<.05\right)$, quality $\left(\beta_{\text {low price }}=-.37, p<\right.$ $\left..01 ; \beta_{\text {high price }}=.38, p<.01\right)$ and value $\left(\beta_{\text {low price }}=-.36, p<.01 ; \beta_{\text {high price }}=.49, p<.001\right)$ satisfying Baron and Kenny's criterion of mediating variable influencing the dependent variables. However 
when perceived difficulty was added as a covariate, the effects of information sort on the dependent variables became weaker suggesting mediation (Table 1).

Depth of Information Search. The number of alternatives viewed, total time spent on the alternatives and on the target product assessed the depth of information search. It was expected that if more time was spent processing information on the alternatives, less time will be spent processing information on the target. There were main effects of information sort [Alternatives viewed: $F_{(1,112)}=16.28, p<.01$; Time ${ }_{\text {target: }} F_{(1,112)}=10.97, p<.01$; Time alternatives $: F_{(1,112)}=$ $18.91, p<.001$ ] and motivation $\mathrm{x}$ information sort on these variables [Alternatives viewed: $F_{(1,}$ ${ }_{112)}=2.76, p=.10$; Time ${ }_{\text {target }}: F_{(1,112)}=4.92, p<.05$; Time alternatives: $\left.F_{(1,112)}=3.57, p<.10\right]$. When motivation to process information was high, those in brand sort conditions viewed far fewer alternatives and spent less time on the target as well as on the alternatives compared to those in price sort conditions (Table 4). When motivation to process information was low, differences between these two sorts on these variables were not significant.

Interestingly in price sort conditions, participants in high motivation conditions spent significantly more time on the alternatives $\left(M_{\text {low motivation }}=67.33 \mathrm{~s}\right.$ vs. $M_{\text {high motivation }}=96.77 \mathrm{~s} ; F$ $(1,58)=5.21, p<.05)$ and even more so on the focal product $\left(M_{\text {low motivation }}=20.93 \mathrm{~s}\right.$ vs. $M_{\text {high }}$ motivation $\left.=38.73 \mathrm{~s} ; F_{(1,58)}=7.82, p<.05\right)$. However the number of alternatives viewed in the two motivation conditions were $\operatorname{similar}\left(M_{\text {low motivation }}=7.57\right.$ vs. $M_{\text {high motivation }}=9.03 ; F_{(1,58)}=2.42$, $p>$.10). This result suggests that though more alternatives were viewed in a price sort and more time was spent on them, the key difference between the two sorts was on the depth of processing of the focal product. It was processed in more detail in price sort conditions when the motivation to process information was also high.

Insert Table 4 about here---- 


\section{Cognitive Responses and Attribute Recall}

Similar to study 1 , cognitive responses (reliability: $I_{r}=0.87 ; \mathrm{M}_{\text {total thoughts }}=3.65$ ) and attribute recall $\left(4 \%\right.$ disagreements; $\left.\mathrm{M}_{\text {accurate }}=1.95 \mathrm{vs} . \mathrm{M}_{\text {total }}=3.11\right)$ were coded by two judges . The motivation $\mathrm{x}$ information sort effects on non-elaborated $\left(F_{(1,116)}=26.53, p<.01\right)$ and elaborated $\left(F_{(1,116)}=35.28, p<.01\right)$ thoughts, and on recall accuracy $\left(F_{(1,108)}=17.98, p<.001\right)$ were similar to those observed in studies 1 and 2 . These results suggest that though there was a deeper processing of information in price sort conditions it occurred only when motivation to process information was high (Table 3). The pattern of thoughts also suggest that brand sort undermined cognitive resources for processing target information affirming that participants relied on its price to make inferences about quality and value (Kardes et al 2004).

\section{GENERAL DISCUSSION}

Although offering more choices to consumers may be desirable, it may also have negative effects on decision quality (Iyengar and Lepper 2000). Hence it is not surprising that in their attempts to help consumers manage a plethora of choices retailers often arrange their offerings on attributes or alternatives. However, such structuring of information in choice situations influences the cognitive effort required to process information and make decisions (Scheibehenne, Greifeneder and Todd 2010; Ariely 2000).

Compared to sorting competing choices by brand names, a price sort will not only increase the number of alternatives considered but also lead to a more complete elaboration of a focal product. Such differences between these two sorts occurred only when participants had a processing goal. As expected, in the absence of processing goals, there were no significant differences between the sorts on processing of the target information. In essence, motivation to process information plays a pivotal role and interacts with how alternatives accompanying a 
target information are sorted (Lee and Ariely 2006; Puccinelli et al 2009). Also, participants in brand sort conditions were unable to re-orient their focus on the target despite being assigned a processing goal. Irrespective of the assigned goals, processing of the target information was impeded when the alternatives were sorted on brand names.

\section{Information Sort and Cognitive Difficulty}

Capacity theorists have argued that mental resources are scarce and can account for performance limitations (Kahneman 1973). Hence, it was not surprising that in study 2 when the secondary task co-opted cognitive resources it impacted processing of target information irrespective of participants' motivation or how the alternatives were sorted. What was more interesting however was that the brand sort overwhelmed participants and performance disruptions were evident in both the primary and secondary tasks. Results from study 3 further revealed that cognitive difficulty created by the accompanying sort explained the mediating mechanisms underlying differences in patterns of target price perceptions.

The cognitive resources available to process target information when the alternatives were sorted on price were apparent in all studies and measured explicitly in study 3 where participants not only spent more time on the target but also on the alternatives. In essence, processing a brand sort usurps cognitive resources while a price sort frees cognitive resources permitting closer scrutiny of the target product. This result is consistent with the conclusion that certain structuring of alternatives may make it difficult for people to choose (Scheibehenne, Greifeneder and Todd 2010).

\section{Information Sort and Processing of Price}

Studies have found that electronic shopping may reduce the cost of search and make price comparisons easier (Haubl and Trifts 2000). The studies reported here suggest that this ease of 
comparison depends upon how the alternatives are sorted. Also, participant's motivation influences whether a target's price will be used more to assess monetary sacrifice or to infer product quality. When motivation was high, lower (higher) price targets were perceived to be lower (higher) in monetary sacrifice but only when with alternatives that were sorted on price than on brand names. This price sort effect is consistent with results from Haubl and Trifts (2000) that showed heightened sensitivity to price information in the presence of a price sort.

When participants had low motivation to process information the observed lack of price sensitivity in presence of a price sort is consistent with results from Lynch and Ariely (2000; also Diehl, Kornish, and Lynch 2003). By showing that motivation to process information moderates the effects of information sort on consumers' assessment of a target's price, these results explain why some studies report that price sort might not impact price sensitivity (Lynch and Ariely 2000; Diehl et al., 2003) while others report its heightened effects (Haubl and Trifts 2000).

\section{Integration of Results}

Since studies 1 and 3 followed similar research designs, the results from these studies were integrated. After confirming that the results from these two studies were statistically homogenous, a quantitative integration of results using meta-analytic procedures was performed (Rosenthal and Rosnow 1991). All of the integrated results were statistically significant, as the confidence interval for the average effect size for each relationship does not include zero (Table 5). The strength of these results can be assessed by determining their sensitivity to additional studies averaging null results $(Z=0.0, p=.50)$. As shown in Table 5 , this tolerance for null results ranged from $n=5$ to $n=14$. That is, it would take 14 studies averaging a null result to make insignificant the result that in high motivation conditions, for a high price target, a price sort will lead to higher perceptions of sacrifice than when alternatives are sorted on brand names. 
Previous studies have shown that when processing sorted information, participants evaluate on average between 12 (Haubl and Trifts 2000) and 20 alternatives (Diehl and Zauberman 2005). The studies reported here presented a similar range of alternatives and the converging results underscore that consumers' price sensitivity is not necessarily a function of the number of alternatives but rather how they are structured and the cognitive difficulty created by them. Brand sorts made it difficult to process information irrespective of the number of alternatives available in such sorts leading to low price sensitivity for a focal product.

Essentially both brand name and price sorts structure alternative choices into categories to help consumers make quality inferences and product decisions. That a price sort leads to a heightened focus on price of the target product shares kinship with results in Simonson, Nowlis and Lemon (1993). Specifically they found that when three alternatives were arranged by brands it decreased the share of the basic feature models (low price) compared to a display by features. Their finding that the focus on features increases when alternatives are arranged by features rather than by brands mirrors the results in our studies. They however explained this pattern of results on the basis of consumers' tendency to avoid extreme options in choice sets. Our results using many more alternatives further suggests that the underlying reasons for consumers' preference might be a limitation of cognitive resources and consequent difficulty in processing information on alternate choices. Such cognitive constraints lead our participants to evaluate a focal product and the alternatives in detail only when the alternatives were arranged on features like price rather than on brand names. In conclusion, the studies reported here also address a research gap identified by Scheibehenne, Greifeneder and Todd' (2010). Those authors stress a need to consider how ease of comparison and purchase goals influences consumers' choices. 


\section{Managerial Implications}

For retailers with relatively higher prices or for those who do not offer discounted prices (i.e., low prices) often, a presentation of alternatives sorted by brand names will result in less thorough evaluation of product information and perceptions of higher quality and value for their offers. However, presenting alternatives sorted on price presents a dilemma and can be a doubleedged sword. Price sorts might be advantageous to retailers who offer relatively low prices or price promotions and want consumers to pay attention to price. When consumers have intentions to purchase, a price sort at such retailers might lead them to perceive their lower priced offers as good value. However, when consumers are browsing, retailers may create impressions of low quality and value for the low price offers and risk damaging their image.

These findings are consistent with research showing that the Internet does not necessarily promote highly price competitive markets or frictionless commerce (Brynjolfsson and Smith 2000). How choices are categorized and the ease of comparison (or lack thereof) constitutes important potential moderators to examine the effects of plethora of choices that are available online and at retailers. Our research further suggests that tools like brand sorts found in portfolios of decision aids at most online retailers and implicitly used by brick and mortar retailers when merchandising on shelves can reduce the importance of using price to assess monetary sacrifice. Arranging alternatives on prices, on the other hand, increases attention to alternative choices but more so to the focal alternative.

\section{Future Research}

Based on past research on dual processing theories, this research conceptualized that sorting of information affects consumers' ability to process information. Hence it implicitly combines both the ability and the opportunity to process information. Additional research should 
examine how consumers with different abilities like those in working memory capacity might respond to an imposed opportunity to process information created by sorting of information. Additionally, do the other forms of sorting information, like by peer ratings of product information work the same way as a brand sort and enhance the value of higher or lower priced target products? Further research is needed to examine the generalizability of these findings and the validity of the conceptual framework. 


\section{REFERENCES}

Alba, Joseph, John Lynch, Barton Weitz, Chris Janiszewski, Richard Lutz, Alan Sawyer, and Stacy Wood (1997). "Interactive Home Shopping: Consumer, Retailer, and Manufacturer Incentives to Participate in Electronic Marketplaces," Journal of Marketing, 61 (July): 38-53.

Ariely, Dan. (2000). "Controlling the Information Flow: Effects on Consumers' Decision Making and Preferences," Journal of Consumer Research, 27 (September): 233-248.

Baddeley, Alan. (2000). "Short-Term and Working Memory," Pp 77-92 in The Oxford Handbook of Memory. E. Tulving and F. I. M. Craik (eds). New York, NY: Oxford University Press.

Boyd, D. Eric and Kenneth D. Bahn. (2009). "When Do Large Product Assortments Benefit Consumers? An Information-Processing Perspective," Journal of Retailing, 85 (3):288-297. Brynjolfsson, Erik, and Michael D. Smith. (2000). "Frictionless Commerce? A Comparison of Internet and Conventional Retailers," Management Science, 46 (4): 563-585.

Chaiken, Shelly and Yacov Trope (1999). Dual-Process Theories of in Social Psychology. New York: Guilford Press.

Diehl, Kristin, Laura J. Kornish, and John G. Lynch, Jr. (2003). "Smart Agents: When Lower Search Costs for Quality Information Increase Price Sensitivity," Journal of Consumer Research, 30 (June): 56-71.

---- and Gal Zauberman. (2005). "Searching Ordered Sets: Evaluations from Sequences under Search," Journal of Consumer Research, 31 (4): 824-832.

Dodds, William. B., Kent B. Monroe, and Grewal, Dhruv. (1991). "Effect of Price, Brand, and Store Information on Buyers' Product Evaluations," Journal of Marketing Research, 28(August), 307-319. 
Grewal, Dhruv, Kent B. Monroe, and R. Krishnan (1998). "The Effect of Price Comparison on Buyers' Perceptions of Acquisition Value, Transaction Value, and Behavioral Intentions," Journal of Marketing, 62 (April), 46-59.

Haubl, Gerald and Kyle B. Murray. (2003). "Preference Construction and Persistence in Digital Marketplaces: The Role of Electronic Recommendation Agents," Journal of Consumer Psychology, 13 (1\&2): 75-91.

---- and Valerie Trifts. (2000). "Consumer Decision Making in Online Shopping Environments: The Effects of Interactive Decision Aids," Marketing Science, 19 (1): 4-21. Hermer-Vazquez, Linda, Elizabeth S. Spelke, and Alla S. Katsnelson (1999). "Sources of Flexibility in Human Cognition: Dual-Task Studies of Space and Language," Cognitive Psychology, 39: 3-36.

Hoffman, Donna L. and Thomas P. Novak (1996). "Marketing in Hypermedia ComputerMediated Environment: Conceptual Foundations," Journal of Marketing, 60 (July): 50-68. Howard Daniel J. and Roger A. Kerin (2006). "Broadening the Scope of Reference Price Advertising Research: A Field Study of Consumer Shopping Involvement," Journal of Marketing, 70 (October): 185-204.

Iyengar, Sheena S. and Mark R. Lepper (2000). "When Choice Is Demotivating: Can One Desire Too Much of a Good Thing?” Journal of Personality and Social Psychology, 79 (6): 9951006.

Kahneman, Daniel (1973). Attention and Effort. Englewood Cliffs, N.J.: Prentice-Hall.

Kardes, Frank R., Maria L. Cronley, James J. Kellaris, and Steven S. Posovac (2004). “The Role of Selective Information Processing in Price-Quality Inference," Journal of Consumer Research, 31 (September): 368-374. 
Kleinmuntz, Don N. and David A. Schkade (1993). "Information Displays and Decision Processes," Psychological Science, 4 (4): 221-227.

Lee, Leonard and Dan Ariely (2006). "Shopping Goals, Goal Concreteness, and Conditional Promotions," Journal of Consumer Research, 33 (1). 60-67.

Lopes, Lola L (1982). "Doing the Impossible: A Note on Induction and the Experience of Randomness," Journal of Experimental Psychology: Learning, Memory and Cognition, 8 (6): 626-636.

Lynch, John G., Jr. and Dan Ariely (2000). "Wine Online: Search Cost and Competition on Price, Quality, and Distribution," Marketing Science, 19 (1): 83-103.

Maheswaran, Durairaj, and Brian Sternthal (1990). "The Effects of Knowledge, Motivation, and Type of Message on Ad Processing and Product Judgments," Journal of Consumer Research, 17 (1): 66-73.

Monroe, Kent B. (2003). Pricing: Making Profitable Decisions. $3^{\text {rd }}$ ed., Burr Ridge, IL: McGraw-Hill/Irwin.

Pashler, Harold (1994). "Dual-Task Interference in Simple Tasks; Data and Theory," Psychological Bulletin, 116 (2), 220-244.

Puccinelli, Nancy M., Ronald C. Goodstein, Dhruv Grewal, Robert Price, Priya Raghubir, and David Stewart (2009). “Customer Experience Management in Retailing: Understanding the Buying Process," Journal of Retailing, 85 (1). 15- 30.

Rao, Akshay R. and Kent B. Monroe (1988). "The Moderating Effect of Prior Knowledge on Cue Utilization in Product Evaluations," Journal of Consumer Research, 19: 253-264.

---- and Wanda A. Sieben (1992). "The Effect of Prior Knowledge on Price Acceptability and the Type of Information Examined," Journal of Consumer Research, 19 (September): 256-270. 
Rosenthal, Robert and Ralph L. Rosnow (1991). Essentials of Behavioral Research: Methods and Data Analysis. New York: NY: McGraw Hill Book Company, Inc.

Scheibehenne, Benjamin, Rainer Greifeneder and Peter M. Todd (2010). "Can There Ever Be Too Many Options? A Meta Analytic Review of Choice Overload," Journal of Consumer Research, 37 (October): 409-425.

Simonson, Itamar, Stephen Nowlis, and Katherine Lemon (1993). "The Effect of Local Consideration Sets on Global Choice Between Lower Price and Higher Quality,” Marketing Science, 12 (Autumn): 357-377.

Suri, Rajneesh and Kent B. Monroe (2003). "The Effects of Time Constraints on Consumers' Judgments of Prices and Products," Journal of Consumer Research, 30 (June): 92-104.

Teasdale, John D., Robert J. Howard, Sally G. Cox, Yvonne Ha, Michael J Brammer, Steven C. R. Williams, and Stuart A. Checkley (1999). "Functional MRI Study of the Cognitive Generation of Affect," American Journal of Psychiatry, 156 (2): 209-215.

Vlaev, Ivo, Nick Chater, Rich Lewis, and Greg Davies. (2009). "Reason-Based Judgments: Using Reasons to Decouple Perceived Price-Quality Correlation," Journal of Economic Psychology, 30: 721-731. 


\section{Table 1}

Sorting and Price Perceptions (Studies $1 \& 3$ )

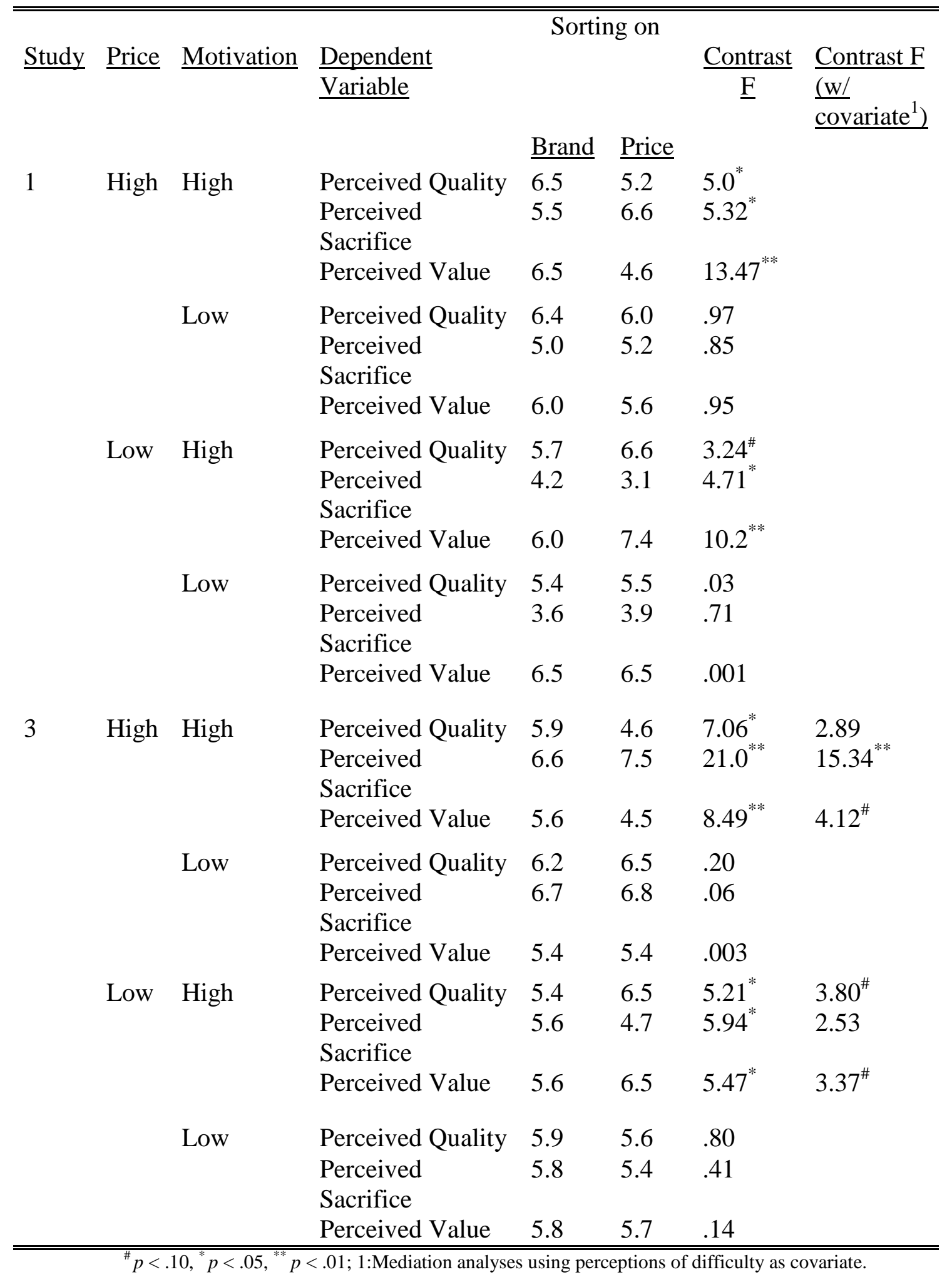


Table 2

Study 2: Sorting and Information Load

\begin{tabular}{|c|c|c|c|c|c|}
\hline \multirow{3}{*}{ Information Load } & \multirow{3}{*}{$\underline{\text { Motivation }}$} & \multicolumn{4}{|c|}{ Sorting on } \\
\hline & & \multirow{2}{*}{$\begin{array}{l}\text { Dependent } \\
\text { Variable }\end{array}$} & \multicolumn{3}{|r|}{ Contrast } \\
\hline & & & $\underline{\text { Price }}$ & Brand. & $\mathrm{F}$ \\
\hline \multirow[t]{6}{*}{ Low } & High & $\begin{array}{l}\text { Perceived } \\
\text { Quality }\end{array}$ & 6.14 & 4.67 & $18.09^{* *}$ \\
\hline & & $\begin{array}{l}\text { Perceived } \\
\text { Sacrifice }\end{array}$ & 3.00 & 4.39 & $14.56^{* *}$ \\
\hline & & $\begin{array}{l}\text { Perceived } \\
\text { Value }\end{array}$ & 6.75 & 5.13 & $24.18^{* *}$ \\
\hline & Low & $\begin{array}{l}\text { Perceived } \\
\text { Quality }\end{array}$ & 4.67 & 5.26 & 1.05 \\
\hline & & $\begin{array}{l}\text { Perceived } \\
\text { Sacrifice }\end{array}$ & 4.68 & 4.40 & .48 \\
\hline & & $\begin{array}{l}\text { Perceived } \\
\text { Value }\end{array}$ & 5.21 & 5.55 & .38 \\
\hline \multirow[t]{6}{*}{ High } & High & $\begin{array}{l}\text { Perceived } \\
\text { Quality }\end{array}$ & 4.84 & 5.35 & .51 \\
\hline & & $\begin{array}{l}\text { Perceived } \\
\text { Sacrifice }\end{array}$ & 4.5 & 4.7 & .23 \\
\hline & & $\begin{array}{l}\text { Perceived } \\
\text { Value }\end{array}$ & 5.23 & 5.42 & .08 \\
\hline & Low & $\begin{array}{l}\text { Perceived } \\
\text { Quality }\end{array}$ & 4.59 & 4.78 & .08 \\
\hline & & $\begin{array}{l}\text { Perceived } \\
\text { Sacrifice }\end{array}$ & 4.50 & 4.95 & 1.3 \\
\hline & & $\begin{array}{l}\text { Perceived } \\
\text { Value }\end{array}$ & 5.75 & 5.50 & .30 \\
\hline
\end{tabular}

${ }^{\#} p<.10,{ }^{*} p<.05,{ }^{* * *} p<.01$ 
Table 3

Sorting and Cognitive Responses

\begin{tabular}{|c|c|c|c|c|c|}
\hline \multirow[t]{2}{*}{$\underline{\text { Study }}$} & \multirow[t]{2}{*}{$\underline{\text { Motivation }}$} & \multirow[t]{2}{*}{$\underline{\text { Proportion of }}$} & \multicolumn{2}{|c|}{$\underline{\text { Sorting on }}$} & \multirow[t]{2}{*}{$\underline{F}$} \\
\hline & & & $\underline{\text { Brand }}$ & Price. & \\
\hline \multirow[t]{6}{*}{1} & High & Elaborated & .05 & .72 & $141.4^{* *}$ \\
\hline & & Non-elaborated & .90 & .26 & $112.2^{* * *}$ \\
\hline & & Accurate Recall & .58 & .91 & $41.95^{* *}$ \\
\hline & Low & Elaborated & .09 & .11 & .08 \\
\hline & & Non-elaborated & .86 & .83 & .22 \\
\hline & & Accurate Recall & .55 & .59 & .36 \\
\hline \multirow[t]{12}{*}{2} & High (Low & Elaborated & .1 & .53 & $144.78^{\text {*** }}$ \\
\hline & Load) & Non-elaborated & .95 & .33 & $89.38^{* *}$ \\
\hline & & Accurate Recall & .31 & .81 & $41.13^{* *}$ \\
\hline & High (High & Elaborated & .05 & .05 & .00 \\
\hline & Load) & Non-elaborated & .92 & .95 & .19 \\
\hline & & Accurate Recall & .30 & .42 & 1.18 \\
\hline & Low (Low & Elaborated & .08 & .03 & 1.29 \\
\hline & Load) & Non-elaborated & .83 & .91 & .79 \\
\hline & & Accurate Recall & .32 & .31 & .003 \\
\hline & Low (High & Elaborated & .06 & .04 & .30 \\
\hline & Load) & Non-elaborated & .92 & .80 & 1.8 \\
\hline & & Accurate Recall & .29 & .31 & .03 \\
\hline \multirow[t]{6}{*}{3} & High & Elaborated & .24 & .83 & $76.2^{* *}$ \\
\hline & & Non-elaborated & .76 & .16 & $77.2^{* *}$ \\
\hline & & Accurate Recall & .39 & .92 & $49.62^{* *}$ \\
\hline & Low & Elaborated & .21 & .27 & .97 \\
\hline & & Non-elaborated & .78 & .70 & 1.58 \\
\hline & & Accurate Recall & .31 & .38 & .79 \\
\hline
\end{tabular}


Table 4

Study 3: Sorting and Information Search

\begin{tabular}{|c|c|c|c|c|c|}
\hline \multirow[b]{2}{*}{$\underline{\text { Price }}$} & \multirow[b]{2}{*}{ Motivation } & \multirow[b]{2}{*}{ Dependent Variable } & \multicolumn{2}{|c|}{ Sorting on } & \multirow[b]{2}{*}{ Contrast F } \\
\hline & & & & & \\
\hline & & & $\underline{\text { Brand }}$ & $\underline{\text { Price }}$ & \\
\hline \multirow[t]{10}{*}{ High } & \multirow[t]{5}{*}{ High } & Perceived Difficulty & 5.8 & 4.6 & $4.09^{*}$ \\
\hline & & Prefer rearrange to price sort & 7.73 & 4.87 & $9.25^{* *}$ \\
\hline & & Total alternatives viewed & 4.9 & 9.5 & $16.06^{* *}$ \\
\hline & & Time spent on target & $18.07 \mathrm{~s}$ & $43.47 \mathrm{~s}$ & $3.96^{*}$ \\
\hline & & Total time on alternatives & 53.27 & $100.67 \mathrm{~s}$ & $5.35^{*}$ \\
\hline & \multirow[t]{5}{*}{ Low } & Perceived Difficulty & 5.4 & 5.3 & .01 \\
\hline & & Prefer rearrange to price sort & 4.0 & 3.53 & .17 \\
\hline & & Total alternatives viewed & 5.87 & 7.9 & 2.3 \\
\hline & & Time spent on target & $11.73 \mathrm{~s}$ & $18.6 \mathrm{~s}$ & 2.1 \\
\hline & & Total time on alternatives & 51.53 & 68.53 & $3.63^{\#}$ \\
\hline \multirow[t]{10}{*}{ Low } & \multirow[t]{5}{*}{ High } & Perceived Difficulty & 6.27 & 4.73 & $4.05^{*}$ \\
\hline & & Prefer rearrange to price sort & 7.93 & 5.93 & $6.78^{* *}$ \\
\hline & & Total alternatives viewed & 5.07 & 8.6 & $5.35^{*}$ \\
\hline & & Time spent on target & $18.27 \mathrm{~s}$ & $34.0 \mathrm{~s}$ & $7.48^{* *}$ \\
\hline & & Total time on alternatives & $50.87 \mathrm{~s}$ & $92.73 \mathrm{~s}$ & $15.22^{* *}$ \\
\hline & \multirow[t]{5}{*}{ Low } & Perceived Difficulty & 5.33 & 5.4 & .02 \\
\hline & & Prefer rearrange to price sort & 4.07 & 2.93 & 1.2 \\
\hline & & Total alternatives viewed & 5.8 & 7.1 & .65 \\
\hline & & Time spent on target & $22.0 \mathrm{~s}$ & $23.27 \mathrm{~s}$ & .50 \\
\hline & & Total time on alternatives & $55.87 \mathrm{~s}$ & $71.93 \mathrm{~s}$ & .96 \\
\hline
\end{tabular}


Table 5

Integrating Results from Studies $1 \& 3^{\mathrm{a}}$

\begin{tabular}{|c|c|c|c|c|c|c|c|}
\hline $\begin{array}{l}\text { Price } \\
\text { Level }\end{array}$ & $\begin{array}{l}\text { Dependent } \\
\text { Variable }\end{array}$ & $\begin{array}{l}\text { Tested } \\
\text { Relationship }\end{array}$ & & $\begin{array}{l}\text { Confidence } \\
\text { Interval }\end{array}$ & \multicolumn{2}{|c|}{ Effect size(r) } & $\begin{array}{l}\text { Tolerance of } \\
\text { Null Result (n) }\end{array}$ \\
\hline High & Perceived Sacrifice & Price sort $>$ & Brand sort & $.37<$ & $<.88$ & .62 & 14 \\
\hline High & Perceived Quality & Price sort < & Brand sort & $.21<$ & $<.72$ & .46 & 7 \\
\hline High & Perceived Value & Price sort < & Brand sort & $.33<$ & $r<.84$ & .59 & 13 \\
\hline Low & Perceived Sacrifice & Price sort < & Brand sort & $.18<$ & $<.69$ & .43 & 6 \\
\hline Low & Perceived Quality & Price sort $>$ & Brand sort & $.14<$ & $<.65$ & .40 & 5 \\
\hline Low & Perceived Value & Price sort $>$ & Brand sort & $.28<$ & $r<.79$ & .53 & 10 \\
\hline
\end{tabular}

a. From high motivation conditions in studies 1 and 3. 


\section{Appendix 1}

\section{Dependent Measures and Manipulation Checks ${ }^{1}$}

Perceptions of Sacrifice $\left(\mathrm{r}_{::}\right.$Study $1=.62$, Study $2=.72$, Study $\left.3=.55\right)$

a.) To buy this Philips DVD player at the offered price I will be spending: A lot of money / Not a lot of money

b.) I feel that this Philips DVD player is: Very Expensive / Very Cheap

Perceptions of Quality (Cronbach's $\alpha .:$ Study $1=.85$; Study $2=.82$, Study $3=.87$ )

a.) This digital player appears to be of good quality

b.) From the given description, this Philips DVD player appears to be of good quality

c.) This digital player seems durable

Perceptions of Value (Cronbach's $\alpha$ : Study $1=.85$; Study $2=.79$, Study $3=.82$ )

a.) The offered price for this Philips DVD player matched the benefits it had to offer

b.) This Philips DVD player appears to be a great deal

c.) At the offered price, this Philips DVD player is probably worth the money

d.) At the offered price, this Philips DVD player is a good value for the money

(All the above items used a 9-point scale \& Strongly Disagree / Strongly Agree as anchors unless specified otherwise)

\section{$\underline{\text { Manipulation Checks }}$}

Motivation to Process (Cronbach's $\alpha:$ Study $1=.80$; Study $2=.78$, Study $3=.82$ ): How motivated were you to read descriptions of the various dvd players / How involved were you while reading the descriptions of the various dvd players / How interested were you in understanding the descriptions of the various dvd players

Perceived Price: The offered price for this Philips DVD player is: Very Low / Very High

\section{Products Used in the Sorted Lists:}

Study 1: Samsung $(98.99,140.99)$, Philips $(98.99,112.99)$, Panasonic (163.99, 169.99), Mintek (149.99, 76.99), JVC (194.99, 99.99), Sony (209.99, 169.99, 129.99), Kenwood (179.99), Toshiba (188.99, 141.99), Sylvania (159.99), Mitsubishi (119.99), Magnavox (95.49), Cyberhome (79.99)

Study 2: Magellan (129.95, 165.95, 199.95); Magellan Maestro (229.95); TomTom (159.95, 219.95, 399.95); Lowrance (169.95); RoadMate (249.95); Garmin (299.95, 499.95); TomTom GO (699.95); Sony (349.95)

Study 3: Acer (899.99, 1249.99), Dell (749.99, 879.99), HP (929.99, 1199.99), Sony (1049.99, 1319.99), Toshiba $(849.99,949.99,959.99,1099.99)$

\footnotetext{
${ }^{1}$ Items were adapted from Grewal, Monroe, and Krishnan (1998) and Dodds, Monroe and Grewal (1991). The items shown refer to the product used in study 1 . These items were modified to reflect the products used in the other studies. Motivation measures are based on Maheswaran and Sternthal (1990).
} 